\title{
Reflets
}

Revue ontaroise d'intervention sociale et communautaire

\section{La santé sexuelle des jeunes femmes afro-francophones de Toronto}

\section{Claire Parrot}

Volume 6, numéro 2, automne 2000

Problèmes sociaux en Ontario français

URI : https://id.erudit.org/iderudit/026326ar

DOI : https://doi.org/10.7202/026326ar

Aller au sommaire du numéro

Éditeur(s)

Reflets : Revue ontaroise d'intervention sociale et communautaire

ISSN

1203-4576 (imprimé)

1712-8498 (numérique)

Découvrir la revue

Citer cet article

Parrot, C. (2000). La santé sexuelle des jeunes femmes afro-francophones de Toronto. Reflets, 6(2), 226-230. https://doi.org/10.7202/026326ar

Tous droits réservés (C) Reflets : Revue ontaroise d'intervention sociale et communautaire, 2000
Ce document est protégé par la loi sur le droit d'auteur. L'utilisation des services d'Érudit (y compris la reproduction) est assujettie à sa politique d'utilisation que vous pouvez consulter en ligne.

https://apropos.erudit.org/fr/usagers/politique-dutilisation/ 


\section{La santé sexuelle des jeunes femmes afro-francophones de Toronto}

\section{Claive Parrot \\ Éducatrice en matière de santé sexuelle, Toronto}

Pour avoir oeuvré dans le domaine de la santé sexuelle pendant plusieurs années, il m'apparait évident que les jeunes femmes afrofrancophones de Toronto veulent savoir, veulent en apprendre de plus en plus sur leur santé sexuelle. Malgré les obstacles imposés par leur culture, ces jeunes femmes désirent grandir au rythme de leur croissance physique et affective. Jusqu'à tout récemment, la seule façon pour nous de les rencontrer était par le biais de la clinique Bay Centre for Birth Control.La planification des naissances constitue, la plupart du temps, le but de leur visite au centre. Force est de réaliser que l'objet d'une telle rencontre se solde bien souvent par l'interruption volontaire d'une grossesse. Cependant, deux questions de taille se posent : qu'en est-il de leur épanouissement sexuel, ce besoin "d'intégrer les aspects somatiques, affectifs, intellectuels et sociaux des êtres sexués qu'elles sont " (Santé Canada 1994 : 6) et bien entendu, comment les rejoindre?

Le centre où nous travaillons permet un entretien initial pour répondre au besoin immédiat de la cliente et offrir un suivi si nécessaire, mais les limites de temps imposées ne permettent pas d'aborder la santé sexuelle. Pour beaucoup de gens, professionnels de la santé comme profanes, le terme sexualité se rapproche davantage de leur réalité que celui de "santé sexuelle ", expression couramment utilisée par les professionnels de cette spécialité. Nous avons pu, à cet égard, observer une évolution sociale du langage. 
Il y a dix ans, il n'était pas courant de voir des clientes demander un service de counselling en sexualité. Depuis quatre ou cinq ans, il appert que les femmes ont moins de réserve à parler du phénomène naturel qu'est la sexualité. Faut-il dire que l'éducation et une plus grande liberté sociale ont contribué à cet état des choses?

Il est assez difficile de parler de sexualité, quelle que soit la culture qui nous a vus grandir, mais nous pouvons affirmer, pour avoir été infirmière-experte dans le domaine, que le sujet est encore grandement tabou dans la société africaine. Les intervenantes et les jeunes filles ne cessent de nous le répéter. Ce qui, par ailleurs, ne veut pas dire que cette société veut demeurer dans l'ignorance. Le réseautage des dix dernières années auprès de divers organismes de la communauté francophone nous a permis d'établir des liens chaleureux avec plusieurs femmes. Il était donc de mise, le moment venu, de proposer et d'organiser des rencontres "sur leur terrain ", c'est-à-dire là où les jeunes femmes se sentent à l'aise, dans de petits espaces où elles se sentent en confiance parmi les leurs. Un organisme en particulier, le Regroupement des jeunes filles francophones de Toronto, nous demandait en mai dernier, d'animer un atelier "santé et prévention " portant sur la santé sexuelle, notamment la contraception et les maladies transmises sexuellement. "Santé et prévention » était un des thèmes suggérés par les jeunes femmes elles-mêmes, dans le cadre d'un sondage effectué dans les écoles francophones pour déterminer les priorités du Premier forum provincial pour les jeunes filles francophones dans toute leur diversité.

L'expérience s'est avérée des plus valables à plusieurs points de vue. D'abord, elle a prouvé que les jeunes participantes, venant pour la plupart de familles afro-francophones, étaient prêtes à ce qu'on leur dise : «oui, il est normal d'avoir une sexualité à 16, 17 et 18 ans; oui il est normal de se poser des questions quant à l'amour des adolescentes tout en pouvant faire un choix éclairé ". Il ne faut pas se leurrer : la grande majorité des jeunes afrofrancophones qui habitent à Toronto veulent vivre au rythme de leurs soeurs de culture canadienne. Elles sont aussi très conscientes que leurs valeurs familiales sont des assises importantes qui les 
unissent aux leurs et qui les soutiennent dans l'intégration à un nouveau pays. Ces jeunes femmes ont tendance à se retrouver entre elles afin de développer des rapports sociaux; les intervenantes, parfois de même culture, mais presque toujours en provenance de pays afro-francophones, sont d'une aide précieuse car elles leur apportent appui et réconfort tout en donnant des lignes directrices pour les guider.

Il est probablement plus facile d'interpréter le contexte de l'événement lorsqu'on comprend les facteurs qui facilitent le processus d'intégration des nouvelles arrivantes. Ces facteurs sont axés sur une parcelle de "chez-soi ", la langue, la culture et une présence maternelle qui comble un peu les vides causés par tant de dépaysement. Les jeunes afro-francophones se le disent et elles ont à coeur de trouver les moyens pour parvenir à se tailler une place dans leur nouveau pays.

Plusieurs pays afro-francophones en voie de développement sont encore dirigés par des dictatures indifférentes au bien-être des habitants. Les valeurs de la religion catholique qui, comme on le sait, n'encourage pas les relations sexuelles en dehors du mariage, sont encore très présentes. Une ville cosmopolite comme Toronto comporte plusieurs religions, cultures et valeurs qui se côtoient tant bien que mal et qui en font sans contredit une ville grouillante d'énergie. Les nouveaux arrivants qui habitent Toronto veulent, malgré un désir sincère d'appartenance, maintenir le peu qu'ils ont de leurs traditions religieuses, avec leur réconfort et avec leur rigidité. On peut néanmoins avoir tendance à oublier que la nature continue son cheminement en faisant fi de la religion et de la culture. On n'a qu'à remonter à saint Augustin, soit au $3^{e}$ et au $4^{\mathrm{e}}$ siècle de notre ère, pour apprendre que ce théologien et grand philosophe a associé l'idée de la sexualité au péché originel et à l'expulsion de l'humanité du paradis terrestre (McKay,1998 : 14). Il n'est pas surprenant, quand on connait la puissance de certaines religions, qu'on doive, plusieurs siècles plus tard, toujours ressentir une certaine culpabilité envers sa sexualité. Il faut toutefois se rendre à l'évidence que l'être humain est un être sexué. Peu importe les entraves, chacun aspire à un meilleur épanouissement sexuel, les jeunes personnes incluses. 
Un atelier, plus intime celui-là, se tenait dernièrement dans un centre communautaire à Toronto où s'étaient rassemblées quelque dix jeunes filles âgées entre treize et vingt ans. Trois intervenantes très bien connues des participantes se joignaient au groupe. L'une d'entre elles connait à fond la culture africaine et possède les habiletés nécessaires à créer le climat de confiance favorable à la participation. Cet atelier se voulait la réponse à un désir exprimé antérieurement par les jeunes filles, celui d'entendre une experte leur parler de santé sexuelle et de pouvoir poser les questions qui les préoccupent et ce, sans être jugées.

Une timidité palpable empêche toutefois les jeunes filles de poser les questions « brûlantes » mentionnées quelques jours auparavant. La glace n'est pas encore tout à fait brisée. Autre constat : il manque encore un je-ne-sais-quoi pour inciter l'auditoire à aller chercher les réponses tant convoitées. Nous entamons le dialogue en définissant la santé sexuelle en termes vulgarisés et en faisant un survol de la contraception, tout en félicitant les jeunes filles du courage qu'elles ont d'aborder un tel sujet. C'est un dialogue de sourdes... L'autre langage par contre, le non-verbal, est évident. Nous décelons l'assentiment de certaines par des hochements de tête approbateurs, des visages dégoûtés à la description des sécrétions vaginales, ou bien des yeux qui s'écarquillent devant un fait nouveau. Nous percevons même chez les intervenantes un intérêt qui en dit long... Qu'est ce qui les empêche de parler? Le fait que la seule femme blanche fasse figure d'autorité? Peut-être. La présence d'autres femmes plus âgées qu'elles? La peur de dire certaines choses qui pourraient froisser? Autre possibilité :c'est intimidant de discuter de ces choses? Assurément.

Nous ne pouvons cependant nous empêcher de nous demander quelle aurait été l'ambiance si nous avions été seule avec elles. Enfin, après un peu d'insistance de la part de l'intervenante qu'elles avaient rencontrée il y a quelques jours, une «brave » ose poser une question sur les maladies transmissibles sexuellement. Le tour est joué. Nous vous rappelons alors que la rencontre a commencé avec une heure de retard, faute d'auditoire. Pourtant, toutes s'étaient dites très intéressées et avaient " promis » qu'elles viendraient. 
Toutefois, un doute subsiste. Un interdit, un obstacle ralentissent un apprentissage qui devrait être facile d'accès pour les jeunes filles que nous avons rencontrées et pour toutes les autres que nous n'avons pas encore rencontrées. L'affaire est délicate et pourtant s'agit-il tout simplement de rappliquer parce que le besoin demeure criant? Ou encore, devrait-on offrir des ateliers de formation aux intervenantes? Enseigner aux enseignants...?

Nous sommes d'avis que c'est là que réside le dilemme; les experts du fascinant champ de la santé sexuelle sont on ne peut plus convaincus du défi qui les attend. Toutefois, il leur faut user de patience et faire preuve de persuasion afin de créer un terrain d'entente avec les personnes influentes auprès de la jeune société afro-francophone. Ces dernières pourront éventuellement accepter qu'on les éduque selon leurs attentes, pour qu'à leur tour, elles puissent assurer dans leur communauté une continuité dans l'enseignement de la santé sexuelle et reproductive. Cette connivence ne pourra que profiter à la diaspora africaine de Toronto. Les jeunes femmes et les jeunes filles d'origine afroafricaine, au même titre que celles de toutes les autres cultures, ont droit à un service de qualité qui ne peut se développer que dans un climat où la collaboration est de rigueur.

\section{Référence bibliographique}

SANTÉ CANADA (1994). Lignes directrices nationales pour l'éducation en matière de santé sexuelle, p. 6. 